\title{
Evaluation Of Average Length of Follow-Up Duration Post Total Knee Arthroplasty: A Survey
}

\section{Pranjali Natu ${ }^{1}$, Diptee Bhole ${ }^{* 2}$.}

${ }^{1}$ Physiotherapist, DES' Brijlal Jindal College of Physiotherapy, Pune, Maharashtra, India.

${ }^{* 2}$ Associate Professor, DES' Brijlal Jindal College of Physiotherapy, Pune, Maharashtra, India.

\section{ABSTRACT}

Background: Among the various diseases in the world, osteoarthritis (OA) is a major contributing factor of disability. Total Knee Arthroplasty (TKA) is a widely performed procedure for advanced arthritis of the knee joint. Both subjective and objective assessments are necessary to evaluate the outcomes post TKA. The physiotherapy treatment program following the surgery is designed in a manner which is best suitable to the patient's need, the efficacy of which will only be determined with regular follow up sessions.

Objectives: The primary objective is to find out length of duration of follow up sessions post TKA with the Physiotherapist. The secondary objectives are to determine whether the reason for termination of follow-up is physiotherapist-based or patient-based and to determine whether the discharge criteria are based on measurable assessment tools.

Purpose: In spite of the surgery being routinely performed, records of time period of follow up with the surgeons and physiotherapists are not maintained. It is also not documented whether the discharge occurs on the basis of formal functional assessments.

Methodology: Pilot study was performed on a group of 10 physiotherapists to calculate the sample size. It was found to be 73. For the final study, candidates fitting in the inclusion criteria were chosen. Oral consent was taken. Self-designed questionnaire in the form of "Google-Form" was administered. The candidates were requested to fill the same. Descriptive analysis of the data obtained was performed to find out the average duration of follow-up post Total Knee Arthroplasty using PRISM Graph-Pad software.

Results: Average (median) length of follow-up duration post TKA was found to be 6.000 weeks. Furthermore, the termination criteria of follow-up were more physiotherapist based and objective in nature.

Conclusion: The time period of follow-up post TKA is inconsistent with the minimum period required for optimal functional recovery of various clinical parameters.

Clinical Implication: A standardized protocol of follow-up post TKA must be devised. The decision making process of termination of follow-up which is based on measurable tools of assessment should be in line with current research findings.

KEY WORDS: Total Knee Arthroplasty, Follow-up, Functional Recovery

Address for correspondence: Dr Diptee Bhole (PT), Associate Professor DES' Brijlal Jindal College of Physiotherapy, Pune, Maharashtra, India. E-Mail: diptee.bhole@despune.org
Access this Article online
Journal Information

Quick Response code

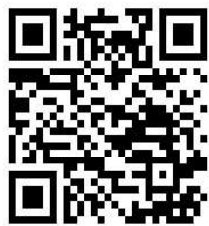

DOI: $10.16965 /$ ijpr.2021.201
International Journal of Physiotherapy and Research ISSN (E) 2321-1822 | ISSN (P) 2321-8975 https://www.ijmhr.org/ijpr.html

DOI-Prefix: https://dx.doi.org/10.16965/ijpr

\section{Article Information}

Received: 27 Sep 2021

Peer Review: 28 Sep 2021

Revised: None
Accepted: 06 Dec 2021

Published (O): 11 Feb 2022

Published (P): 11 Feb 2022

\section{INTRODUCTION}

Among the various diseases in the world, osteoarthritis (OA) ranked fourth for the contributing factor of disability. OA is chronic, degenerative disease of the joint which affects articular cartilage that is associated with pain, swelling, functional deficit. OA affects joints like the knee, hip, ankle, wrist, cervical, and 
lumbar spine. $22 \%-39 \%$ of 1.252 billion population suffer from OA in India [1]. Total Knee Arthroplasty is a widely performed procedure for advanced arthritis of the knee joint. The important goals are to decrease pain and improve patient's physical function and quality of life [2].

A joint registry has been established by the Indian Society of Hip and Knee Surgeons (ISHKS). It has been collecting data for the last 6 years. Data of 34,478 TKA from the ISHKS was assessed and it included 8612 males (25\%) and 25,866 females (75\%). The average age of the patients was 64.4 years (For Osteoarthritis 45 to 88 years and for Rheumatoid arthritis 22 to 74 years). The indication for TKA was osteoarthritis in $97 \%$ and rheumatoid arthritis in $2.2 \%$ of the cases [3].

Total knee arthroplasty (TKA) provides patients significant benefits with regard to quality of life, pain relief and function. This gives them a high degree of patient satisfaction [4].

Postoperative outpatient rehabilitation with balance training aids in recovery of balance, mobility, and functional outcomes in patients with knee osteoarthritis after TKA [5].

Range of Motion (ROM) positively co-related with functional outcome and patient satisfaction after TKA. These findings indicate that increased ROM after TKA is a significant factor for functional outcome and satisfaction in Asian patients [6].

The high association between quadriceps strength and functional performance suggests that postoperative quadriceps strengthening could be vital to enhance the potential advantages of TKA. Quadriceps strength was the most highly correlated measure associated with functional performance [7].

The recovery of strength and function following Unilateral Total Knee Arthroplasty (UTKA) had steadied by 1 year and during the following year further improvements were marginal [8].

A correlation analysis shows that due to weak leg extensor muscles, an excessive load is applied to knee joint during mid stance of gait in patients. However, in healthy subjects, stronger muscles surrounding the knee joint provide better knee joint loading during gait [9].

According to a study by Bolink et al, in 2015, there was moderate co-relation between Western Ontario and McMaster Osteoarthritis Index (WOMAC) and Knee Injury and Osteoarthritis Outcome Score (KOOS) outcome measures with Gait, sit to stand Transfers and Block Step up Transfers, which were evaluated pre-operatively and 1 year post- operatively [10].

Walking ability and speed are crucial to the TKA patient and are a representation of their pain and function [11].

Need of study: It has been stated in current literature that objective as well as subjective clinical parameters have a bearing on functional outcomes post TKA surgery [11].

The important subjective clinical parameters include pain, quality of life and patient satisfaction. The important objective clinical outcomes include strength of quadriceps femoris, range of motion at the knee, balance, proprioception and gait parameters.

It has been previously reported that pain improved significantly at 3 months on an average [12-14], while quality of life showed significant improvement at 12 months ${ }^{(15,16)}$ and patient satisfaction and well-being improved at 12 months [17-19], post operatively. It was also observed in literature that strength of quadriceps declined in the first month but showed significant improvements up-to 1year post operatively [20-24]. Knee range of motion attained maximal values at 6.5 months post operatively while it continued to improve till 2 years and gained a peak value of 116 degrees at 2 years [25].

The maximum improvements in knee ROM should be expected within the first 12 weeks. Minor changes can be seen up-to 26 weeks after TKA. Additionally, concomitant factors like age and pre-surgery knee ROM are associated with the gains in knee ROM. They should also be factored into the approximation of expected knee ROM at a given follow-up interval after TKA [26]. Balance and proprioception improved as compared to pre-operative levels at 1year post operatively [27]. 
Gait parameters improved at 12 weeks post the surgery [28].

According to the ISHKS registry, 17,124 Primary TKA were performed in 2018, with contributions to the registry by 281 surgeons all over India [29]. In the location of this current study, TKA surgery is commonly performed in superspeciality hospitals.

Studies in other locations claim that up to $30 \%$ of patients experience continual pain and functional limitations following TKA [30].

What achieves the recoveries post-operatively, is a continuous out-patient based or homebased rehabilitation protocol along-with a follow-up with the surgeon, physiotherapist and ancillary team including nurses [31-37]. Literature also shows effectiveness of Telerehabilitation as a mode of follow-up $[38,39]$.

Better functional outcomes are associated with better values of subjective as well as objective clinical parameters. These clinical parameters require varied timelines to recover according to the aforementioned studies. However, the importance of a minimum follow-up period of one year cannot be undermined to achieve optimal functional recovery.

In spite of this surgery being routinely performed, records of time period of follow up with the surgeons and physiotherapists are not maintained. It is also not documented whether the discharge occurs on the basis of formal functional assessments.

The current study attempts to find the average length of follow up duration with physiotherapists. It also tries to establish who decides the time of discharge and whether the discharge is based on measurable functional assessments.

\section{METHODOLOGY}

Study design- Observational

Study Setting- Hospitals, Private Clinics

Study Population- Physiotherapists

Sample Size- 73

Sampling technique- Purposive

Inclusion Criteria- Physiotherapists involved in post-operative rehabilitation and having an experience of at least one year.

Exclusion criteria- Physiotherapists unwilling to participate.

Procedure: Pilot study was performed on a group of 10 physiotherapists to calculate the sample size. It was found to be 73 . For the final study, candidates fitting in the inclusion criteria were chosen. Oral consent was taken. Self-designed questionnaire in the form of "Google-Form" was administered. The candidates were requested to fill the same. Descriptive analysis of the data obtained was performed to find out the average duration of follow-up post TKA. The PRISM Graph-Pad software was used for the same.

\section{DATA ANALYSIS AND RESULTS}

\section{A. Demographics of participants}

Fig. 1: Type of practice the participants are involved in.

\begin{tabular}{lc}
\hline \multicolumn{1}{c}{ Type } & Percentage (\%) \\
\hline Private Clinic & 30.5 \\
\hline Hospital & 20.8 \\
\hline Both & 25 \\
\hline Home Visits & 9.7 \\
\hline Combination & 13.8 \\
\hline
\end{tabular}

Fig. 2: Work Experience of participants.

\begin{tabular}{cc}
\hline $\begin{array}{c}\text { Work Experience } \\
\text { (in years) }\end{array}$ & $\begin{array}{c}\text { Percentage } \\
\text { (\%) }\end{array}$ \\
\hline $\mathbf{0 1 - 0 3}$ & 43 \\
\hline $\mathbf{0 4 - 0 7}$ & 30.6 \\
\hline $\mathbf{0 8 - 1 1}$ & 13.9 \\
\hline $\mathbf{1 2 - 1 5}$ & 8.3 \\
\hline $\mathbf{1 6 - 1 9}$ & 1.4 \\
\hline$>20$ & 2.8 \\
\hline
\end{tabular}

\section{B. Results}

Fig. 3: Maintenance of Follow-up post-discharge with the Physiotherapist.

\begin{tabular}{cc}
\hline Response & Percentage (\%) \\
\hline Yes & 83.3 \\
\hline No & 1.4 \\
\hline Occasionally & 15.2 \\
\hline
\end{tabular}

Fig. 4: Nature of follow-up.

\begin{tabular}{cc}
\hline Nature & Percentage (\%) \\
\hline OPD visits & 36.11 \\
\hline Home visits & 63.88 \\
\hline Telephone & 0 \\
\hline
\end{tabular}




\section{Average Duration of Follow-up with the Physiotherapist post TKA}

Number of values- 72

Descriptive analysis of the data obtained was performed. Skewness was found to be 2.198, which is higher than the acceptable value. Hence, median of the data was calculated. It was found to be 6.000 weeks.

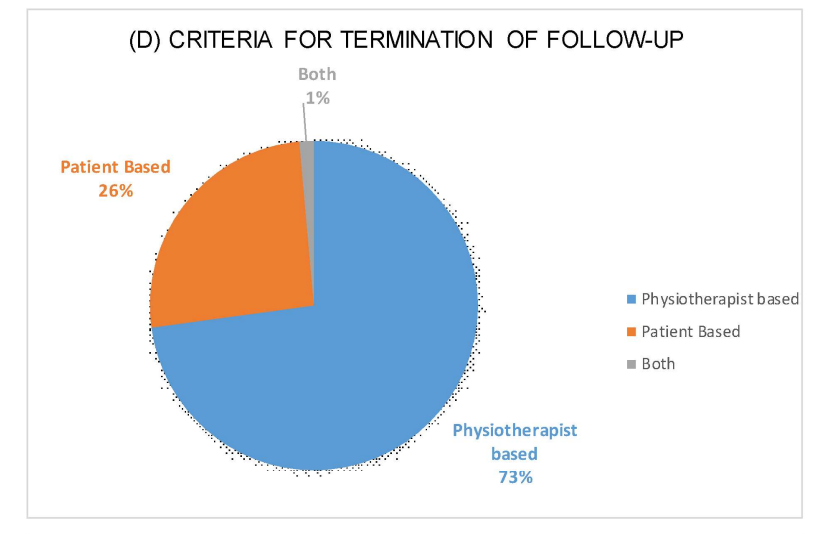

(D1) FACTORS DETERMINING TERMINATION

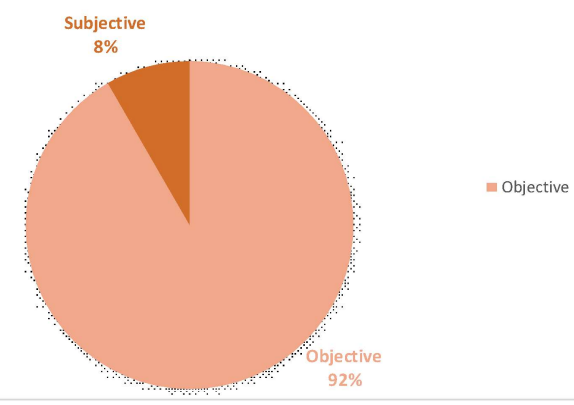

(E) OBJECTNE FACTORS

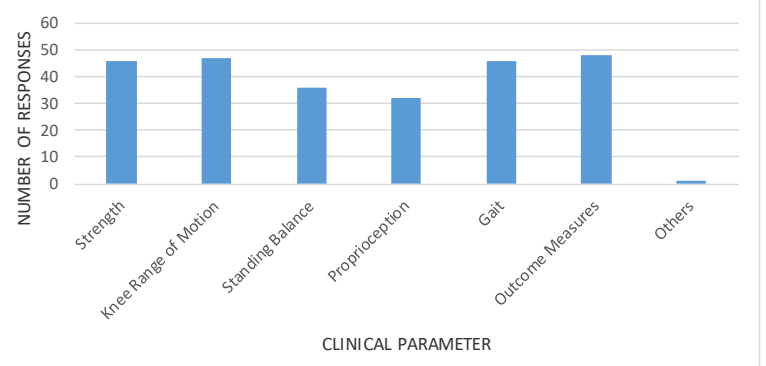

\section{DISCUSSION}

Descriptive analysis of the data obtained was performed. Median was calculated as a measure of central tendency as the data was skewed. Median of follow-up duration was found to be six weeks.

Better functional outcomes post TKA are associated with better values of subjective as well as objective clinical parameters [41]. These clinical parameters require varied timelines to recover according to various studies [21-29]. The importance of a minimum follow-up period of 1 year cannot be undermined to achieve functional recovery. The data shows that the average follow-up duration post TKA with physiotherapists in the location of this study is 6 Weeks. As shown in pie chart $D$, the termination criteria of follow-up are more physiotherapist based than patient based. Further, according to pie chart D1, 92\% of the physiotherapist based criteria are objective in nature. These, as shown in graph E include- strength of quadriceps, ROM of knee joint, standing balance, proprioception, gait parameters and functional outcome measures. However, it may be stated that it is unlikely for the aforementioned objective measures to achieve optimal functional recovery with a follow-up duration of 6 weeks.

Due to the ambiguity raised by the previous findings, further exploration of the tools used for the assessment of objective clinical parameters was attempted. Though this was not a part of the original objectives, it led to the following information- Strength of Quadriceps was assessed using Manual Muscle Testing (MMT). MMT is known to be subjective in nature. Hence a more objective assessment using equipment like dynamometer is desirable [44].

Knee ROM was assessed using goniometry which is an objective measure. Subjective measures like "end feel" and "presence of flexion deformity" were also used for the assessment. Goniometric assessment should be preferred as it is standardized and uniform [45].

Proprioception was indirectly evaluated by assessing stability and balance in functional activities like walking and standing. This method of assessment is subjective in nature too and can produce incorrect results. Therefore, use of objective measures like Joint Position Sense Testing is appropriate $[46,47]$.

Standing Balance and Gait were assessed by performing observational analysis, which too, is a subjective measure. Balance Evaluation Systems Test (BEST) is a reliable tool to assess standing balance in patients post TKA $[48,49]$. Thus, most of the above tools of assessment do not qualify as objective measures. Hence, 
a misinterpretation of the recovery of clinical parameters may be a likely reason for an early termination of follow-up post TKA in the location of this study.

Limitations: The study was limited to the therapists practicing in Pune and Mumbai cities. The study did not differentiate between Unilateral and Bilateral TKA.

Future scope: A longitudinal study exploring reasons for non-compliance of follow-up by the patient can be done.

\section{CONCLUSION}

The average length of follow-up duration post TKA in the location of this study is 6 weeks. It is inconsistent with the minimum period required for optimal functional recovery of various clinical parameters.

\section{ABBREVIATIONS}

OA- Osteoarthritis

TKA- Total Knee Arthroplasty

ROM- Range of Motion

WOMAC- Western Ontario and McMaster Universities Osteoarthritis Index

KOOS- Knee injury and Osteoarthritis Outcome Score

\section{Authors' contributions}

Pranjali Natu- Questionnaire Design and Data Collection, Data Collation and Analysis, Manuscript Writing. https://orcid.org/0000-0002-8718-5006

Dr. Diptee Bhole (PT)- Development of study topic. Guidance with questionnaire formulation, data analysis and final results.

https://orcid.org/0000-0002-6447-2547

\section{Conflicts of interest: None}

\section{REFERENCES}

[1]. Samuel AJ, Kanimozhi D. Outcome measures used in patient with knee osteoarthritis: With special importance on functional outcome measures. Int J Health Sci (Qassim). 2019;13(1):52-60.

[2]. Lynn Allen Colby, Carolyn Kisner, John DeWitt. The Knee- Joint surgery and Post-operative management. In: Therapeutic Exercise- Foundation and Techniques. New Delhi, India: Jaypee Brothers Medical; 2012. p. 778.

[3]. Pachore JA, Vaidya SV, Thakkar CJ, Bhalodia HK, Wakankar HM. ISHKS joint registry: A preliminary report. Indian J Orthop. 2013;47(5):4103 00195413118208.

[4]. Canovas F, Dagneaux L. Quality of life after total knee arthroplasty. Orthop Traumatol Surg Res. 2018 Feb;104(1S):S41-S46.
[5]. Liao CD, Lin LF, Huang YC, Huang SW, Chou LC, Liou TH. Functional outcomes of outpatient balance training following total knee replacement in patients with knee osteoarthritis: a randomized controlled trial. Clin Rehabil. 2015 Sep;29(9):855-67.

[6]. Ha CW, Park YB, Song YS, Kim JH, Park YG. Increased Range of Motion Is Important for Functional Outcome and Satisfaction After Total Knee Arthroplasty in Asian Patients. J Arthroplasty. 2016 Jun;31(6):1199-1203.

[7]. Mizner RL, Petterson SC, Snyder-Mackler L. Quadriceps strength and the time course of functional recovery after total knee arthroplasty. J Orthop Sports Phys Ther. 2005 Jul;35(7):424-36.

[8]. Barker KL, Jenkins C, Pandit H, Murray D. Muscle power and function two years after unicompartmental knee replacement. Knee. 2012;19(4):360-4.

[9]. Vahtrik D, Gapeyeva H, Ereline J, Pääsuke M. Relationship between leg extensor muscle strength and knee joint loading during gait before and after total knee arthroplasty. Knee. 2014;21(1):216-20.

[10]. Bolink SAAN, Grimm B, Heyligers IC. Patient-reported outcome measures versus inertial performance-based outcome measures: A prospective study in patients undergoing primary total knee arthroplasty. Knee. 2015;22(6):618-23.

[11]. Graff C, Hohmann E, Bryant AL, Tetsworth K. Subjective and objective outcome measures after total knee replacement: is there a correlation? ANZ J Surg. 2016 Nov;86(11):921-925.

[12]. Gandhi R, Mahomed NN, Cram P, Perruccio AV. Understanding the relationship between 3-month and 2-year pain and function scores after total knee arthroplasty for osteoarthritis. J Arthroplasty. 2018;33(5):1368-72.

[13]. Lenguerrand E, Wylde V, Gooberman-Hill R, Sayers $A$, Brunton $L$, Beswick $A D$, et al. Trajectories of pain and function after primary hip and knee arthroplasty: The ADAPT cohort study. PLoS One. 2016;11(2):e0149306.

[14]. Wylde V, Penfold C, Rose A, Blom AW. Variability in long-term pain and function trajectories after total knee replacement: A cohort study. Orthop Traumatol Surg Res. 2019;105(7):1345-50.

[15]. Brandes $M$, Ringling $M$, Winter C, Hillmann A, Rosenbaum D. Changes in physical activity and health-related quality of life during the first year after total knee arthroplasty. Arthritis Care Res (Hoboken). 2011;63(3):328-34.

[16]. Papakostidou I, Dailiana ZH, Papapolychroniou T, Liaropoulos L, Zintzaras E, Karachalios TS, et al. Factors affecting the quality of life after total knee arthroplasties: a prospective study. BMC Musculoskelet Disord. 2012;13(1):116.

[17]. Nilsdotter AK, Toksvig-Larsen S, Roos EM. Knee arthroplasty: are patients' expectations fulfilled? A prospective study of pain and function in 102 patients with 5-year follow-up: A prospective study of pain and function in 102 patients with 5-year follow-up. Acta Orthop. 2009;80(1):55-61. 
[18]. Loš ák J, Gallo J, Zapletalová J. Patient satisfaction after total knee arthroplasty. Analysis of pre-operative and Peri-operative parameters influencing results in 826 patients. Acta Chir Orthop Traumatol Cech. 2016;83(2):94-101.

[19]. March LM, Cross MJ, Lapsley H, Brnabic AJ, Tribe $\mathrm{KL}$, Bachmeier $\mathrm{CJ}$, et al. Outcomes after hip or knee replacement surgery for osteoarthritis. A prospective cohort study comparing patients' quality of life before and after surgery with age-related population norms. Med J Aust. 1999;171(5):235-8.

[20]. Barker KL, Jenkins C, Pandit H, Murray D. Muscle power and function two years after unicompartmental knee replacement. Knee. 1016;2012;19(4):360-364.

[21]. Nerhus TK, Heir S, Svege I, Skråmm I, Jervidalo T, Madsen JE, et al. Time-dependent improvement in functional outcome following Oxford medial unicompartmental knee arthroplasty. A prospective longitudinal multicenter study involving 96 patients: A prospective longitudinal multicenter study involving 96 patients. Acta Orthop. 2012;83(1):46-52.

[22].Vahtrik D, Gapeyeva H, Ereline J, Pääsuke M. Relationship between leg extensor muscle strength and knee joint loading during gait before and after total knee arthroplasty. Knee. 1016;2014; 21(1):216-220.

[23]. Yoshida Y, Mizner RL, Ramsey DK, Snyder-Mackler L. Examining outcomes from total knee arthroplasty and the relationship between quadriceps strength and knee function over time. Clin Biomech (Bristol. 1016;Aon). 2008;23(3):320-328.

[24]. Stevens-Lapsley JE, Balter JE, Wolfe P, Eckhoff DG, Kohrt WM. Early neuromuscular electrical stimulation to improve quadriceps muscle strength after total knee arthroplasty: a randomized controlled trial. Phys Ther. 2012;92(2):210-26.

[25]. Nerhus TK, Heir S, Thornes E, Madsen JE, Ekeland A. Time-dependent improvement in functional outcome following LCS rotating platform knee replacement: A prospective longitudinal study in 50 patients. Acta Orthop. 2010;81(6):727-32.

[26]. Mehta S, Rigney A, Webb K, Wesney J, Stratford PW, Shuler FD, et al. Characterizing the recovery trajectories of knee range of motion for one year after total knee replacement. Physiother Theory Pract. 2020;36(1):176-85.

[27]. Schwartz I, Kandel L, Sajina A, Litinezki D, Herman A, Mattan $Y$. Balance is an important predictive factor for quality of life and function after primary total knee replacement. J Bone Joint Surg Br. 2012;94(6):782-6.

[28]. B'czkowicz D, Skiba G, Czerner M, Majorczyk E. Gait and functional status analysis before and after total knee arthroplasty. Knee. 2018 Oct;25(5):888-896.

[29]. ISHKS [Internet]. Ishks.com. [cited 2021 May 26]. Available from: http://www.ishks.com]

[30]. Yang HY, Losina E, Lange JK, Katz JN, Collins JE. Longitudinal Trajectories of Pain and Function Improvement Following Total Knee Replacement. ACR Open Rheumatol. 1002;2019;1(5):308-317.
[31]. Medical Advisory Secretariat. Physiotherapy rehabilitation after total knee or hip replacement: an evidence-based analysis. Ont Health Technol Assess Ser. 2005;5(8):1-91.

[32]. Warren M, Kozik J, Cook J, Prefontaine P, Ganley K. A comparative study to determine functional and clinical outcome differences between patients receiving outpatient direct physical therapy versus home physical therapy followed by outpatient physical therapy after total knee arthroplasty. Orthop Nurs. 2016;35(6):382-90.

[33]. Akodu AK, Giwa SO, Akinbo SRA, Ahmed UA. Physiotherapy in the management of total knee arthroplasty: a review. Nig Q J Hosp Med. 2011;21(2):99-105.

[34]. Lenssen AF, de Bie RA. Role of physiotherapy in peri-operative management in total knee and hip surgery. Injury. 2006;37 Suppl 5:S41-3.

[35]. Grotle M, Garratt AM, Klokkerud M, Løchting I, Uhlig T, Hagen KB. What's in team rehabilitation care after arthroplasty for osteoarthritis? Results from a multicenter, longitudinal study assessing structure, process, and outcome. Phys Ther. 2010;90(1):121-31.

[36]. Mahomed NN, Koo Seen Lin MJ, Levesque J, Lan S, Bogoch ER. Determinants and outcomes of inpatient versus home based rehabilitation following elective hip and knee replacement. J Rheumatol. 2000;27(7):1753-8.

[37]. Kramer JF, Speechley M, Bourne R, Rorabeck C, Vaz $\mathrm{M}$. Comparison of clinic- and home-based rehabilitation programs after total knee arthroplasty. Clin Orthop Relat Res. 2003;410(410):225-34.

[38]. Eichler S, Salzwedel A, Rabe S, Mueller S, Mayer F, Wochatz $M$, et al. The effectiveness of telerehabilitation as a supplement to rehabilitation in patients after total knee or hip replacement: Randomized controlled trial. JMIR Rehabil Assist Technol. 2019;6(2):e14236.

[39].Shukla H, Nair SR, Thakker D. Role of telerehabilitation in patients following total knee arthroplasty: Evidence from a systematic literature review and meta-analysis. J Telemed Telecare. 2017;23(2):339-46.

[40]. Harikesavan K, Chakravarty RD, Maiya AG. Influence of early mobilization program on pain, self-reported and performance based functional measures following total knee replacement. J Clin Orthop Trauma. 2019;10(2):340-4.

[41]. Bindawas SM, Graham JE, Karmarkar AM, Chen $\mathrm{N}-\mathrm{W}$, Granger CV, Niewczyk P, et al. Trajectories in functional recovery for patients receiving inpatient rehabilitation for unilateral hip or knee replacement. Arch Gerontol Geriatr. 2014;58(3):344-9.

[42]. Khanna G, Singh JA, Pomeroy DL, Gioe TJ. Comparison of patient-reported and clinician-assessed outcomes following total knee arthroplasty. J Bone Joint Surg Am. 2011 Oct 19;93(20):e117(1)-(7).

[43]. Doma K, Grant A, Morris J. The effects of balance training on balance performance and functional outcome measures following total knee arthroplasty: A systematic review and meta-analysis. Sports Med. 2018;48(10):2367-85. 
[44]. Bohannon RW. Manual muscle testing: does it meet the standards of an adequate screening test? Clin Rehabil. 2005;19(6):662-7.

[45]. Hancock GE, Hepworth T, Wembridge K. Accuracy and reliability of knee goniometry methods. J Exp Orthop. 2018;5(1):46.

[46]. Elangovan N, Herrmann A, Konczak J. Assessing proprioceptive function: evaluating joint position matching methods against psychophysical thresholds. Phys Ther. 2014;94(4):553-61.

[47]. Hillier S, Immink M, Thewlis D. Assessing proprioception: A systematic review of possibilities: A systematic review of possibilities. Neurorehabil Neural Repair. 2015;29(10):933-49.

[48]. Chan ACM, Ouyang XH, Jehu DAM, Chung RCK, Pang MYC. Recovery of balance function among individuals with total knee arthroplasty: Comparison of responsiveness among four balance tests. Gait Posture. 2018;59:267-71.
[49]. Chan ACM, Pang MYC. Assessing balance function in patients with total knee arthroplasty. Phys Ther. 2015;95(10):1397-407.

[50]. Gagnier JJ, Mullins M, Huang H, Marinac-Dabic D, Ghambaryan A, Eloff B, et al. A systematic review of measurement properties of patient-reported outcome measures used in patients undergoing total knee arthroplasty. J Arthroplasty. 2017;32(5):1688-1697.e7.

[51]. Walker LC, Clement ND, Deehan DJ. Predicting the outcome of total knee arthroplasty using the WOMAC score: A review of the literature. J Knee Surg. 2019;32(8):736-41.

How to cite this article: Pranjali Natu, Diptee Bhole.Evaluation Of Average Length of Follow-Up Duration Post Total Knee Arthroplasty: A Survey. Int J Physiother Res 2022;10(1):4088-4094. DOI: 10.16965/ijpr.2021.201 